\title{
Bélgica: um país europeu de médio porte se adaptando a novas realidades de política externa e cooperação*
}

\section{Belgique: un pays européen de taille moyenne en adaptation à des nouvelles réalités de politique externe et coopération}

\section{Resumo}

Este artigo trata da palestra proferida pelo embaixador Josef Smets no dia 05 de junho de 2013 no Centro Universitário de Brasília (UniCEUB). A Bélgica, país europeu de médio porte, hospeda grandes instituições e organizações internacionais e supranacionais, obtendo, assim, papeis de destaque no âmbito internacional desde a sua independência no século XIX. Atualmente, no cenário da União Europeia, o país aparece como defensor da integração europeia e centro cosmopolita de instituições de ensino e pesquisa. No Pós-Guerra, intensifica-se sua Política de Cooperação, em que, em diversos momentos, vê-se fundir interesses da política interna com política externa.

Palavras-chave: Bélgica. Organizações Internacionais. Política de Cooperação. Política interna. Política externa.

\section{Résumé}

Cet article traite de la conférence faite par l'embassadeur Josef Smets le 05 juin 2013 au Centro Universitário de Brasília (UniCEUB). La Belgique, un pays européen d'extension territoriale moyenne, accueille des grandes institutions et organisations internationales et supranationales, en ayant, ainsi, des rôles importants dans le cadre international depuis son indépendance au XIX siècle. Actuellement, dans le scenario de l'Union Européenne, le pays apparaît comme un défenseur de l'intégration européenne et centre cosmopolite d'institutions d'enseignement et recherche. À l'Après-Guerre, on voit intensifier sa Politique de Coopération, dans laquelle, dans plusieurs moments, on voit se mélanger des intérêts de la politique interne avec ceux de la politique externe.

Mots-clés: Belgique. Organisations internationales. Politique de Coopération. Politique interne. Politique externe.

Artigo recebido em: 14/08/2013.

Aprovado em 30/09/2013

Texto baseado na palestra proferida pelo Embaixador Jozef Smets no dia 05 de junho de 2013 no UniCeub

Embaixador da Bélgica em Brasília. 
Com 11 milhões de habitantes, a Bélgica, um dos países fundadores do processo de integração européia, pode ser considerada um país de médio porte na Europa. Nós sempre dizemos que “a Bélgica está bem situada", e nós, diplomatas belgas, nunca nos esquecemos de mencionar o fato de que estamos hospedando as maiores instituições e organizações internacionais e supranacionais, como por exemplo, a Organização do Tratado do Atlântico Norte (OTAN) e grandes instituições da União Européia, transformando a nossa capital, Bruxelas, em um lugar cosmopolita, onde todos se sentem bem-vindos.

Desde sua Independência, em 1830, a Bélgica tem sido um membro muito participativo e engajado na comunidade internacional, mostrando boas habilidades lingüísticas, e, por isso, ocupando papéis de destaque nas instituições multilaterais.

Todavia, há outro ponto fundamental na nossa política externa: a Bélgica é uma nação com um importante setor comercial, mantendo boas relações com todos, embora deva ser dito que $72 \%$ do comércio belga é intra-UE (ou seja, realizada dentro da União Européia), enquanto que apenas $8 \%$ com os países da América e 10\% com os países da Ásia.

Deixe-me falar um pouco sobre outros pontos importantes como a política externa da Bélgica no pós-guerra: abordagem que transcende um governo ou um partido político.

A primeira regra fundamental é, certamente, o fato de que a Bélgica é defensora da integração européia. Essa tem sido uma posição contínua desde a Segunda Guerra Mundial, apoiada por praticamente todos os partidos políticos e pela maior parte da opinião pública.

Devo dizer que até mesmo a recente "crise do euro" leva ao meu país à convicção de que são necessárias fortes instituições financeiras e econômicas Européias.

Outro elemento-chave é, com muita lógica, a preservação de uma relação intensa com os países vizinhos, dos quais três (Alemanha, França e Países Baixos) são os nossos principais parceiros comerciais. Por coincidência, os três idiomas nacionais da Bélgica são os mesmos destes países, embora, devo dizer que a comunidade belga de língua alemã é minoria no leste do país.
Em terceiro lugar está nossa especial relação transatlântica com os EUA, mais um ponto importante que raramente é questionado.

Além disso, posso mencionar as redes de contatos regionais e estrangeiras, tais como o grupo de países de língua francesa, que transformam a Bélgica em um membro muito dedicado da Organização Internacional da Francofonia (OIF). Vale esclarecer que as Regiões belgas têm suas próprias competências, e que por isso a Fédération Wallonie Bruxelles é muito influente em parcerias com outras regiões ou países de língua francesa.

Finalmente, devo mencionar outros dois parâmetros: um "tradicional" e outro mais recente.

$\mathrm{Na}$ verdade, a Bélgica tem uma "presença tradicional" na África Central, uma afirmação perigosa, pós-colonial, mas que significa, em termos mais modernos, que temos mantido contatos fortes e construtivos com alguns países africanos, com base no que chamamos de "um passado comum" (com tudo o que isso implica ...).

Um exemplo disso é a nossa relação com a República Democrática do Congo que é, ao mesmo tempo, muito rica e delicada. Nossa Embaixada em Kinshasa é um dos maiores postos diplomáticos que temos no mundo, mas, não se preocupem, as missões diplomáticas belgas, em geral, são bastante modestas.

Em seguida, temos o parâmetro mais recente: nossa diplomacia ágil, incluindo a diplomacia econômica, com os países do BRICS, incluindo o Brasil, a partir da qual nossas redes diplomáticas vêm sendo incrementadas.

Depois de ter comentado alguns "elementos sabidos" da política externa belga, menciono algumas mudanças importantes que ocorreram a partir dos anos sessenta, como por exemplo, na nossa política de cooperação.

Com base em uma abordagem paternalista, os interesses da cooperação e do comércio se colidiam (projetos eram executados por empresas belgas!), e passavam por uma aproximação estressante de parceria. Sendo Embaixador da Bélgica no Burundi, de 2008 a 2012, um país situado na África Central e importante parceiro de cooperação, participei com freqüência em diálogos sobre projetos e no diálogo político que temos em diferentes setores com nossos parceiros do Burundi.

Ao longo dos anos, a Bélgica respeitou os "Princípios de Paris" e outras diretrizes da política de coope- 
ração internacional, tais como: pequeno número de parceiros de cooperação e programas mais importantes em setores bem definidos (significando uma relação séria de parceria com o país beneficiário), integração dos projetos nas prioridades nacionais do país beneficiário, uma clara separação entre projetos de desenvolvimento e os interesses de empresas belgas no exterior.

Com dezenas de parceiros, a cooperação belga se reestruturou e manteve apenas 18 países como prioritários. Apesar disto devo admitir que a Bélgica ainda não atingiu o critério definido pelas Nações Unidas de atribuir $0,7 \%$ de seu PIB para a cooperação internacional, e, devo dizer que a crise atual na Europa não está nos ajudando a atingir este objetivo.

Algumas palavras sobre os atores-chave na política externa (e de cooperação) belga:

Ministro das Relações Exteriores desde 2011, o Sr. Didier Reynders (que fez uma visita ao Brasil em abril deste ano) é certamente um ator fundamental: com base nas grandes linhas da ação governamental e nas "diretrizes clássicas" da nossa política exterior, ele é a pessoa que deu início a essas grandes linhas de ação deixando nelas suas marcas próprias.

Além dele, outros atores da política exterior devem ser mencionados.

A importância dos Ministros da Cooperação para o Desenvolvimento e da Defesa são muito visíveis no cenário internacional. Como exemplos, cito a cooperação bilateral no setor da defesa com a República Democrática do Congo (RDC) e o Burundi e a recente participação da Bélgica nos esforços internacionais para restabelecer a paz e o Estado de direito no Mali, no Afeganistão e na Líbia.

Como eu disse, a Bélgica é um Estado Federal, constituído por Regiões e Comunidades que possuem funções a nível internacional, podendo celebrar acordos no âmbito de suas competências.

Como um diplomata leal ao Estado Federal, costumo dizer que somos mais fortes e mais eficientes quando trabalhamos juntos e em harmonia. Provavelmente, este é um dos maiores desafios para um diplomata belga que deve se manter dedicado à diplomacia e ao mesmo tempo estar aberto a iniciativas específicas das Regiões de Flandres, da Valônia e de Bruxelas (Capital) e das três comunidades lingüísticas cujos idiomas são o holandês, o francês e $o$ alemão.

Em se tratando de atores importantes na política externa da Bélgica, certamente não posso esquecer-me do Rei - no dia 21 de julho deste ano, o príncipe herdeiro tornou-se Philippe I, Rei dos Belgas, com a abdicação de seu pai, o Rei Albert II. Nesse contexto, freqüentemente falamos sobre o Palácio Real, o Primeiro-Ministro (embora nosso atual Primeiro-Ministro, o Sr. Elio di Rupo, pareça ter um perfil mais reservado quanto à política exterior, isso não exclui a possibilidade de que efetue em breve uma visita importante ao Brasil), o Parlamento (o Presidente da Câmara belga, André Flahaut, visitará Brasília em novembro deste ano ), as províncias, entre outros.

Fortes e presentes no exterior são também as agências de promoção comercial das Regiões de Flandres e da Valônia, com escritórios próprios no Brasil (São Paulo).

Não devemos esquecer que todos os ministros belgas participam de uma base regular em diferentes setores da UE, em que a política externa e a política interna se tornam uma só.

Permitam-me concluir com algumas palavras sobre as relações belgo-brasileiras. Se posso dizer algo com certeza, então digo que estão se intensificando e se tornando cada vez mais importante, embora ... não sejam recentes.

Teremos o prazer de apresentar, durante uma cerimônia que será organizada no Congresso Nacional, em Brasília, um livro sobre os "Cinco séculos de relação entre Belgas e Brasileiros", resultado de uma cooperação entre especialistas belgas e brasileiros.

Dizemos "belgas" e "brasileiros" porque ambos os países ainda não eram independentes.

Como historiador, estou muito interessado em ler esse livro, composto por dezenas de contribuições de curta e fácil leitura, como por exemplo... uma sobre o comportamento de marinheiros brasileiros que, no século XVI, estavam muito infelizes na cidade portuária de Antuérpia , quando, à noite, as portas da cidade se fechavam ...

Isto faz parte da história, mas, por favor, vamos olhar juntos para o futuro. Muitas vezes, fico surpreso ao constatar, em encontros oficiais ou não, que meus interlocutores conhecem muitas coisas sobre a Bélgica, principalmente sobre Bruxelas e Brugges, sobre os chocola- 
tes, as cervejas e também sobre Tintin. As pessoas dão a entender que sabem que somos uma sociedade aberta e moderna.

É tarefa nossa encontrar meios de ampliar nossas perspectivas de alguma forma e de lançar novas iniciativas em outros setores e que a Bélgica não é somente sinônimo de chocolate, mas também de excelentes universidades, de uma pesquisa científica de alto nível e de uma cultura contemporânea e cosmopolita.
A esse respeito, não esquecerei o que a Presidenta do Brasil me disse muito espontaneamente, quando entreguei minhas credenciais em janeiro deste ano: "Oh, Bélgica! Nós gostaríamos muito de trabalhar em conjunto com o seu país tanto no setor portuário, quanto na cooperação científica e tecnológica em parceria com suas excelentes universidades."

Temos muito a fazer, mas não começaremos do zero. Afinal, cinco séculos não é pouca coisa... 